\title{
Beneficial effect of 24-month bilateral subthalamic stimulation on quality of sleep in Parkinson's disease
}

\author{
Haidar S. Dafsari ${ }^{1,2}$ (1) K. Ray-Chaudhuri ${ }^{2,3} \cdot$ Keyoumars Ashkan $^{2} \cdot$ Lena Sachse $^{1} \cdot$ Picabo Mahlstedt $^{1}$. \\ Monty Silverdale ${ }^{4} \cdot$ Alexandra Rizos ${ }^{2} \cdot$ Marian Strack $^{1} \cdot$ Stefanie T. Jost ${ }^{1} \cdot$ Paul Reker $^{1} \cdot$ Michael Samuel $^{2}$. \\ Veerle Visser-Vandewalle ${ }^{5} \cdot$ Julian Evans $^{4} \cdot$ Angelo Antonini $^{6,7} \cdot$ Pablo Martinez-Martin $^{8} \cdot$ Lars Timmermann $^{1,9}$. \\ EUROPAR, the IPMDS Non Motor P.D. Study Group
}

Received: 6 November 2019 / Revised: 27 December 2019 / Accepted: 1 February 2020 / Published online: 9 March 2020

(c) The Author(s) 2020

\begin{abstract}
Background Subthalamic nucleus (STN) deep brain stimulation (DBS) improves quality of life (QoL), motor, and sleep symptoms in Parkinson's disease (PD). However, the long-term effects of STN-DBS on sleep and its relationship with QoL outcome are unclear.

Methods In this prospective, observational, multicenter study including 73 PD patients undergoing bilateral STN-DBS, we examined PDSleep Scale (PDSS), PDQuestionnaire-8 (PDQ-8), Scales for Outcomes in PD-motor examination, -activities of daily living, and -complications (SCOPA-A, -B, -C), and levodopa-equivalent daily dose (LEDD) preoperatively, at 5 and 24 months follow-up. Longitudinal changes were analyzed with Friedman-tests or repeated-measures ANOVA, when parametric tests were applicable, and Bonferroni-correction for multiple comparisons. Post-hoc, visits were compared with Wilcoxon signed-rank/t-tests. The magnitude of clinical responses was investigated using effect size.

Results Significant beneficial effects of STN-DBS were observed for PDSS, PDQ-8, SCOPA-A, -B, and -C. All outcomes improved significantly at 5 months with subsequent decrements in gains at 24 months follow-up which were significant for PDSS, PDQ-8, and SCOPA-B. Comparing baseline and 24 months follow-up, we observed significant improvements of PDSS (small effect), SCOPA-A (moderate effect), -C, and LEDD (large effects). PDSS and PDQ-8 improvements correlated significantly at 5 and 24 months follow-up.

Conclusions In this multicenter study with a 24 months follow-up, we report significant sustained improvements after bilateral STN-DBS using a PD-specific sleep scale and a significant relationship between sleep and QoL improvements. This highlights the importance of sleep in holistic assessments of DBS outcomes.
\end{abstract}

Keywords Deep brain stimulation · Subthalamic nucleus · Non-motor symptoms · Quality of life · Parkinson's disease sleep scale

$\begin{array}{ll}\text { Abbreviations } & \\ \text { DBS } & \text { Deep brain stimulation } \\ \text { LEDD } & \text { Levodopa equivalent daily dose } \\ \text { PDSS } & \text { Parkinson's Disease Sleep Scale } \\ \text { PDQ-8 SI } & \text { 8-Item PD Questionnaire Sum- } \\ & \text { mary Index } \\ \text { QoL } & \text { Quality of life }\end{array}$

Members of the Non-motor Parkinson's Disease Study Group of the International Parkinson's and Movement Disorders Society are listed in the Acknowledgement section.

Haidar S. Dafsari

haidar.dafsari@uk-koeln.de

Extended author information available on the last page of the article
SCOPA-A, -B, and -C Scales for outcomes in PD-motor examination, activities of daily living, and motor complications

STN Subthalamic nucleus

\section{Introduction}

Subthalamic nucleus (STN) deep brain stimulation (DBS) is a safe and effective treatment option improving quality of life (QoL) [18], motor [28], and non-motor symptoms (NMS) [14] in patients with advanced Parkinson's disease (PD) who suffer from motor complications or pharmacotherapy-refractory tremor [46]. 
In patients with $\mathrm{PD}$, sleep symptoms are common and associated with QoL impairments [44]. Previous studies, using PD-specific clinician-rated scales [14] and patientbased self-reported questionnaires $[4,25,37,38]$, have provided evidence for beneficial effects of STN-DBS on sleep symptoms [38]. More recently, a study by Choi et al. found significant sustained improvements in sleep disturbances up to 3 years after STN-DBS [6]. But the study was limited by the single center design of their study, the cohort sample size (45 patients completed the last follow-up, and the mean disease duration of patients (17.2 years \pm 6.2 ), which is longer than most DBS studies [12, 18, 49, 51].

These results were supported by studies using polysomnography which showed an improvement of sleep architecture $[1,7,35]$, time of wakefulness after sleep onset $[1,7$, 37], time of REM sleep time [35, 37], and periodic limb movements [3]. However, long-term beneficial effects on sleep symptoms and if these relate to an improvement of QoL after STN-DBS have not been studied sufficiently. A study by Lyons et al. reported negative results for daytime sleepiness at 24 months follow-up after STN-DBS but did not investigate overall quality of sleep and nocturnal sleep symptoms [30].

Here we report subjective sleep symptoms at 5 months and 24 months follow-up in patients with PD undergoing STN-DBS. We hypothesized that sleep symptoms significantly improve from baseline to 24 months follow-up and that this beneficial effect is significantly correlated with an improvement of QoL after STN-DBS.

\section{Materials and methods}

\section{Design and ethical approval}

This is an ongoing, prospective, observational, multicenter, international study including consecutively enrolled patients from three DBS centers (Cologne, Manchester, and London) as part of the NILS study [9]. It was authorized by local ethics committees (United Kingdom: NRES SouthEast London REC3, 0000010084; 10/H0808/141; Cologne 012-145, German Clinical Trials Register: \#6735) and was carried out in accordance with the Declaration of Helsinki. All patients gave written consent prior to study procedures.

\section{Participants}

PD diagnosis was based on the UK Brain Bank criteria and DBS screening was carried out according to guidelines of the International PD and Movement Disorders Society. Patients were considered eligible for DBS treatment if the levodopa test resulted in $>30 \%$ improvement of motor examination assessed by the Unified PD Rating Scale-III. Patients were excluded from DBS treatment if clinically relevant neuropsychological or neuropsychiatric disorders were found in assessments by a multi-disciplinary team including specialized neuropsychiatrists and neuropsychologists.

\section{Clinical assessment}

Patients were assessed at baseline (MedON) and at 5 and 24 months follow-up visits after surgery (MedON/StimON) with following scales:

(1) Sleep symptoms: the patient-based self-reported PD Sleep Scale (PDSS) was employed to investigate fifteen disease-specific aspects of sleep rated on a visual analog scale (item 1: 'Overall sleep quality', item 2: 'Sleep onset insomnia', item 3: 'Sleep maintenance insomnia', item 4 'Nocturnal restlessness in legs or arms', item 5: 'Fidgeting in bed', item 6: 'Distressing dreams at night', item 7: 'Distressing hallucinations at night', item 8: 'Nocturia', item 9: 'Urinary incontinence due to motor OFF', item 10: 'Wakefulness due to numbness/tingling', item 11: 'Wakefulness due to painful muscle cramps', item 12: 'Early waking due to painful posturing', item 13: 'Tremor on wake up', item 14: 'Sleep refreshment', item 15: 'Unexpectedly falling asleep at daytime'). The clinimetric properties of the overall PDSS and its specific items and their strong relationship with other sleep-wake disorder scores (e.g. the strong correlation between PDSS item 15 and the Epsworth Sleepiness Scale) have been well established $[5,50]$. PDSS items respectively range from 0 (maximum impairment) to 10 (no impairment). Therefore, the PDSS total score ranges from 0 (maximum impairment) to 150 (no impairment).

(2) QoL: the PD Questionaire-8 (PDQ-8) has previously been used in patients with PD and STN-DBS $[13,47]$. The PDQ is recommended for assessments of QoL by the Movement Disorders Society Scales Committee [33] and commonly used for DBS studies in PD [18, 45]. Results are reported as PDQ-8 Summary Index (PDQ-8 SI) to help the interpretation of results and simplify comparisons with other studies. The PDQ-8 SI ranges from 0 (no impairment) to 100 (maximum impairment).

(3) Mood disorder: the Hospital Anxiety and Depression Scale subscales for anxiety and depression (HADS-A and -D) was used to examine specific mood disorders $[11,42]$. The HADS-A and -D subscale range from 0 (no anxiety/depression) to 21 (maximum anxiety/ depression).

(4) Motor disorder: the Scales for Outcomes in PD (SCOPA)-A, -B, and -C were used to assess respectively motor examination, activities of daily living, and 
motor complications. The SCOPA is an abbreviated version of the Unified PD Rating Scale from which it was derived [31] and the two scales highly correlate [32]. The SCOPA-A, $-\mathrm{B}$, and $-\mathrm{C}$ range from 0 (no impairment) to 42,21 , and 12 respectively (maximum impairment).

(5) The therapeutic medical regimen was recorded calculating the total levodopa equivalent daily dose (LEDD) and the LEDD of dopamine agonists according to the method of Tomlinson et al. [49].

\section{Statistical analysis}

Normality of distribution of clinical scores was tested with the Shapiro-Wilk method. Significant longitudinal changes of outcome parameters were analyzed with Friedman-tests or repeated-measures ANOVA, when parametric tests were applicable. As we used multiple tests, the Bonferroni-correction for multiple comparisons was applied. The already corrected $p$-values are presented here (significance threshold: $p=0.05$ ). Post-hoc Wilcoxon signed-rank t-tests, respectively were employed to investigate significant changes between the three visits. To investigate the magnitude of changes, we calculated effect sizes ([mean Test ${ }_{\text {visit } 1}-$ mean Test $\left._{\text {visit } 2}\right] / \mathrm{SD}$ Test $_{\text {visit 1 }}$ ) [8] and relative changes ([mean Test $_{\text {visit } 2}-$ mean Test $_{\text {visit } 1}$ ]/mean Test visit $2_{\text {). }}$.

Furthermore, we investigated the relationship between changes of all outcome parameters at 24 months followup by computing Spearman correlations between change scores $\left(\right.$ Test $_{\text {change scores }}=$ Test $_{\text {baseline }}-$ Test $\left._{\text {follow-up }}\right)$. We also explored Spearman correlations for change scores from 5 to 24 months follow-up for LEDD (total and dopamine agonist) and PDSS (total score and items).

\section{Results}

The study included 73 patients (47 males) with PD undergoing bilateral STN-DBS. Patients were aged 61.9 years \pm 7.7 with 10.4 years \pm 5.0 disease duration. The median Hoehn and Yahr was 2.5 (interquartile range: 2.0-3.0).

\section{Clinical outcomes at baseline, 5 months, and 24 months follow-up}

Friedman-tests, repeated-measures ANOVA resulted in significant longitudinal changes of all outcome parameters (see Table 1 and Fig. 1). Comparing baseline to 5 months followup, post-hoc Wilcoxon signed-rank, $t$-tests found significant improvements of all outcome parameters (all $p<0.001$ ) with subsequent decrements in these gains from 5 to 24 months follow-up. This decrement reached statistical significance for PDSS total score, PDQ-8 SI, HADS-D (all $p<0.001$ ),
HADS-A $(p=0.011)$, and SCOPA-B $(p=0.011)$. Nonetheless, comparing baseline to 24 months follow-up, significant beneficial effects of bilateral STN-DBS were observed for PDSS total score, SCOPA-A, -B, -C, total LEDD, and dopamine agonists LEDD (SCOPA-B $p=0.046$, all other $p<0.001)$.

Effect sizes from baseline to 5 months follow-up were 'small' for HADS-A and -D, 'moderate' for PDQ-8 SI, SCOPA-A, -B, and dopamine agonists LEDD, and 'large' for PDSS, SCOPA-C, and total LEDD (see Table 2). From baseline to 24 months follow-up effect sizes were 'small' for PDSS and SCOPA-B, 'moderate' for SCOPA-A, -C, and dopamine agonists LEDD, and 'large' for total LEDD.

We recorded psychotropic medication in all patients: stable treatment regimens from baseline to last assessment were administered for two patients with quetiapine (25 and $50 \mathrm{mg}$ ), one patient with agomelatine $(25 \mathrm{mg})$, one patient with amitriptyline (100 mg), one patient with opipramole (50 mg), and one patient with citalopram (50 mg). In two patients psychotropic medication changed during the course of the study: one patient was switched from mirtazapine (30 $\mathrm{mg}$ ) to quetiapine $(100 \mathrm{mg}$ ) at 5 months follow-up as visual hallucinations had developed and one patient was postoperatively started on quetiapine $(150 \mathrm{mg})$ as the patient developed suicidal ideation.

\section{Explorative analyses of PDSS items at baseline, 5 months, and 24 months follow-up}

Friedman-tests for PDSS items found significant longitudinal changes of all items except 'Nocturia' (see Table 1).

Comparing baseline to 5 months follow-up, post-hoc Wilcoxon tests resulted in significant improvements of 'overall sleep quality' $(p<0.001)$, 'sleep onset insomnia' ( $p=0.003)$, 'sleep maintenance insomnia' $(p<0.001)$, 'nocturnal restlessness in legs or arms' $(p<0.001)$, 'fidgeting in bed' ( $p=0.001)$, 'distressing hallucinations at night' $(p=0.006)$, 'urinary incontinence during motor OFF' $(p=0.020)$, 'wakefulness due to numbness/tingling' ( $p=0.012)$, 'wakefulness due to painful muscle cramps' $(p=0.004)$, 'early waking due to painful posturing' ( $p=0.001)$, 'tremor on wake up' $(p=0.002)$, 'sleep refreshment' $(p=0.029)$, and 'unexpectedly falling asleep at daytime' $(p<0.001)$.

Comparing baseline to 24 months follow-up, post-hoc Wilcoxon tests resulted in significant improvements of 'overall sleep quality' $(p<0.001)$, 'sleep maintenance insomnia' ( $p=0.001)$, 'early waking due to painful posturing' $(p=0.014)$, 'tremor on wake up' $(p<0.001)$, and 'unexpectedly falling asleep at daytime' $(p=0.003)$. In contrast, a significant worsening was observed for 'distressing dreams at night' $(p=0.030)$. No significant changes were found for other PDSS items. 
Fig. 1 Parkinson's Disease Sleep Scale at preoperative baseline and postoperative follow-up at 5 and 24 months

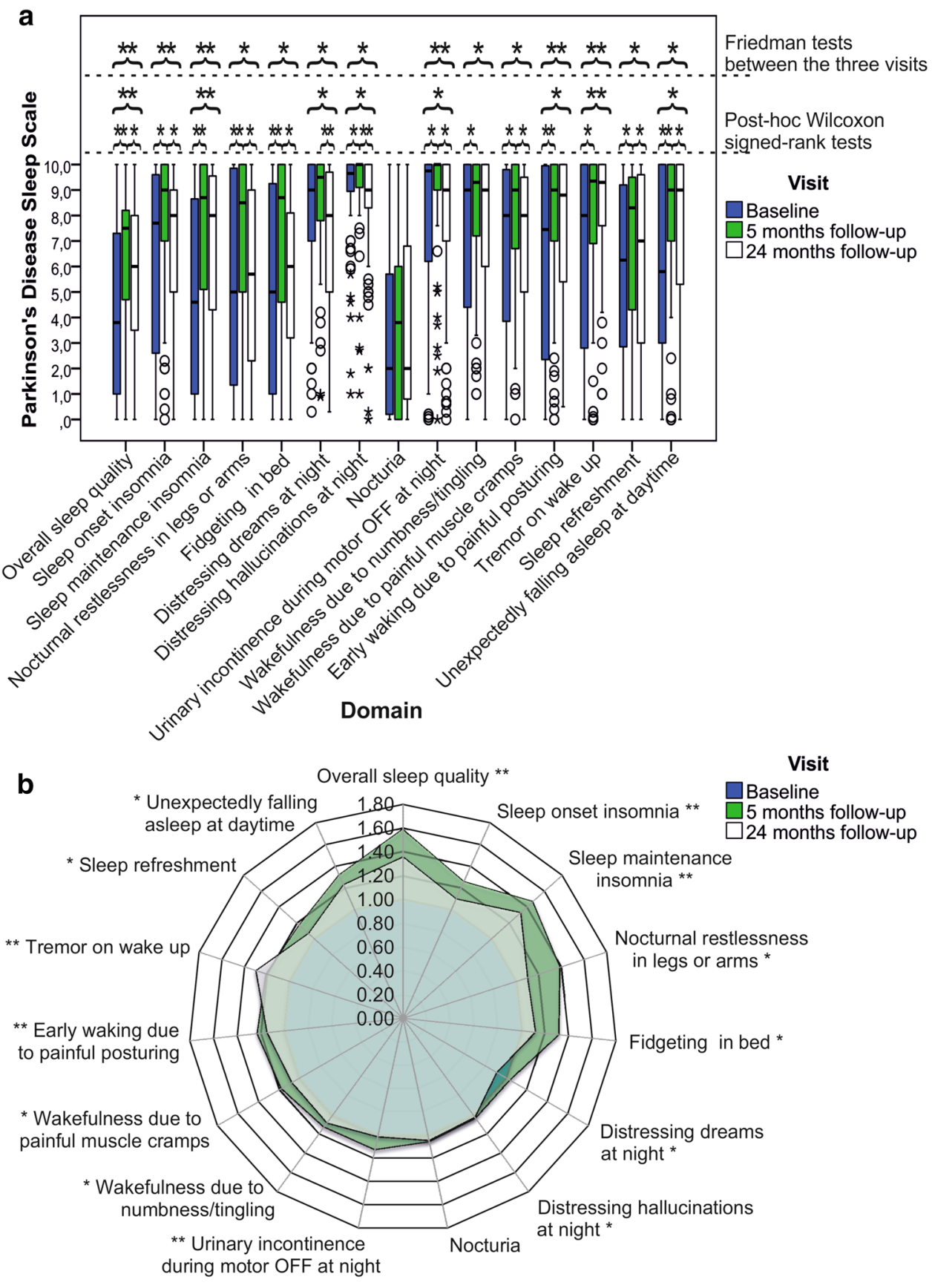

Effect sizes of improvements from baseline to 24 months follow-up were 'small' for 'overall sleep quality', 'wakefulness due to numbness/tingling', 'early waking due to painful posturing', 'unexpectedly falling asleep at daytime', and 'moderate' for, 'sleep maintenance insomnia' and 'tremor on wake up' (see Table 2). For PDSS items with worsening scores at 24 months follow-up, 'small' effect sizes were found for 'distressing dreams at night' and 'distressing hallucinations at night'. Other effect sizes were negligible.

\section{Explorative correlation analyses between outcome parameters at 5 months and $\mathbf{2 4}$ months follow-up}

PDSS total score improvement significantly correlated with improvements of PDQ-8 SI and SCOPA-C at 24 months follow-up (see Table 3). No significant correlations were found for improvements of SCOPA-A and -B, HADS-A and $-\mathrm{D}$, and LEDD reduction (total and dopaminagonists). Explorative analyses of change scores (1) from baseline to 24 months follow-up and (2) from 5 to 24 months follow-up 
Table 1 Outcome parameters at baseline, 5 months and 24 months follow-up

\begin{tabular}{|c|c|c|c|c|c|c|c|c|c|}
\hline & \multirow[t]{2}{*}{$n$} & \multicolumn{2}{|c|}{ Baseline } & \multicolumn{2}{|c|}{$\begin{array}{l}5 \text { Months } \\
\text { follow-up }\end{array}$} & \multicolumn{2}{|c|}{$\begin{array}{l}24 \text { Months } \\
\text { follow-up }\end{array}$} & \multirow[t]{2}{*}{$p^{\mathrm{a}}$} & \multirow[t]{2}{*}{ Post-hoc tests ${ }^{b}$} \\
\hline & & Mean & SD & Mean & SD & Mean & SD & & \\
\hline PDSS total score $* *$ & 66 & 90.0 & 25.3 & 111.1 & 22.9 & 98.9 & 22.1 & $<0.001$ & $a^{\neq}, b^{\neq}, c^{\neq}$ \\
\hline PDSS item 1: 'overall sleep quality' ** & 67 & 4.2 & 3.1 & 6.5 & 2.6 & 5.7 & 2.8 & $<0.001$ & $a^{\ddagger}, b^{\ddagger}, c$ \\
\hline PDSS item 2: 'sleep onset insomnia' ** & 68 & 6.3 & 3.6 & 7.8 & 2.8 & 7.0 & 2.9 & 0.001 & $\mathrm{a}, \mathrm{c}$ \\
\hline PDSS item 3: 'sleep maintenance insomnia' $* *$ & 66 & 4.8 & 3.7 & 7.2 & 3.1 & 6.7 & 3.0 & $<0.001$ & $a^{\ddagger}, b^{\ddagger}$ \\
\hline PDSS item 4: 'nocturnal restlessness in legs or arms' * & 68 & 5.0 & 3.8 & 6.9 & 3.4 & 5.4 & 3.3 & 0.002 & $a^{\ddagger}, c$ \\
\hline PDSS item 5: 'fidgeting in bed' * & 68 & 5.2 & 3.8 & 6.8 & 3.4 & 5.8 & 3.1 & 0.026 & $a^{\neq}, c$ \\
\hline PDSS item 6: 'distressing dreams at night' * & 67 & 7.9 & 2.8 & 8.2 & 2.7 & 7.3 & 2.7 & 0.027 & $\mathrm{~b}, \mathrm{c}^{\neq}$ \\
\hline PDSS item 7: 'distressing hallucinations at night' $*$ & 68 & 8.8 & 2.0 & 9.3 & 1.8 & 8.4 & 2.4 & 0.002 & $\mathrm{a}, \mathrm{c}^{\ddagger}$ \\
\hline PDSS item 8: 'nocturia' & 67 & 3.4 & 3.5 & 3.5 & 3.3 & 3.4 & 3.3 & 0.497 & \\
\hline PDSS item 9: 'urinary incontinence during motor OFF' $* *$ & 68 & 7.8 & 3.3 & 8.7 & 2.4 & 7.7 & 3.0 & 0.001 & $\mathrm{a}, \mathrm{c}$ \\
\hline PDSS item 10: 'wakefulness due to numbness/tingling' * & 68 & 6.9 & 3.4 & 7.9 & 2.9 & 7.7 & 2.8 & 0.049 & a \\
\hline PDSS item 11: 'wakefulness due to painful muscle cramps' * & 67 & 6.5 & 3.3 & 7.7 & 2.8 & 7.1 & 3.0 & 0.005 & $\mathrm{a}, \mathrm{c}$ \\
\hline PDSS item 12: 'early waking due to painful posturing' $* *$ & 68 & 6.3 & 3.7 & 7.7 & 3.0 & 7.3 & 3.1 & $<0.001$ & $a^{\neq}, b$ \\
\hline PDSS item 13: 'tremor on wake up' $* *$ & 66 & 6.2 & 3.8 & 7.8 & 3.2 & 8.3 & 2.3 & $<0.001$ & $a, b^{\neq}$ \\
\hline PDSS item 14: 'sleep refreshment' * & 68 & 5.8 & 3.5 & 6.8 & 3.2 & 6.2 & 3.4 & 0.014 & $\mathrm{a}, \mathrm{c}$ \\
\hline PDSS item 15: 'unexpectedly falling asleep at daytime' $*$ & 67 & 5.9 & 3.7 & 7.8 & 3.0 & 7.3 & 3.0 & 0.004 & $a^{\ddagger}, b, c$ \\
\hline PDQ-8 SI ** & 72 & 33.1 & 17.1 & 22.7 & 14.1 & 30.1 & 18.7 & $<0.001$ & $a^{\neq}, c^{\neq}$ \\
\hline HADS-A & 70 & 5.9 & 3.7 & 4.6 & 3.3 & 5.4 & 4.1 & 0.002 & $a^{\neq}, c$ \\
\hline HADS-D & 70 & 4.9 & 3.0 & 3.9 & 2.9 & 5.2 & 3.2 & 0.006 & $\mathrm{a}, \mathrm{c}^{\ddagger}$ \\
\hline SCOPA-A ** & 67 & 12.6 & 6.0 & 8.6 & 4.9 & 9.1 & 5.0 & $<0.001$ & $a^{\ddagger}, b^{\ddagger}$ \\
\hline SCOPA-B $* *$ & 71 & 7.7 & 3.6 & 5.6 & 2.8 & 6.7 & 3.8 & $<0.001$ & $a^{\ddagger}, b, c$ \\
\hline SCOPA-C ** & 71 & 5.3 & 3.1 & 2.8 & 2.6 & 2.9 & 2.4 & $<0.001$ & $a^{\neq}, b^{\neq}$ \\
\hline LEDD total $(\mathrm{mg}) * *$ & 69 & 1103.8 & 503.4 & 641.4 & 365.1 & 702.3 & 442.0 & $<0.001$ & $a^{\ddagger}, b^{\ddagger}$ \\
\hline LEDD dopamine agonists $(\mathrm{mg}) * *$ & 69 & 293.0 & 245.4 & 153.9 & 139.3 & 133.4 & 116.2 & $<0.001$ & $a^{\ddagger}, b^{\ddagger}$ \\
\hline
\end{tabular}

Bold font highlights significant results

$H A D S-A$ and $-D$ Hospital Anxiety and Depression Scale-anxiety and -depression subscales, LEDD levodopa equivalent daily dose, $P D S S$ Parkinson's Disease Sleep Scale, $P D Q-8$ SI 8-item Parkinson's Disease Questionnaire Summary Index, SCOPA- $A$, $-B,-C$ Scales for Outcomes in Parkinson's disease-motor examination, -activities of daily living, -motor complications

Post-hoc comparisons (Wilcoxon signed-rank or $t$-tests):

Baseline vs 5 months follow-up: $\mathrm{a}=$ significant $(p<0.05) ; \mathrm{a}^{\ddagger}=$ highly significant $(p \leq 0.001)$

Baseline vs 24 months follow-up: $\mathrm{b}=$ significant $(p<0.05) ; \mathrm{b}^{\ddagger}=$ highly significant $(p \leq 0.001)$

5 vs 24 months follow-up: $\mathrm{c}=$ significant $(p<0.05) ; \mathrm{c}^{\dagger}=$ highly significant $(p \leq 0.001)$

*Significant difference between visits ( $p<0.05$, Friedman test or repeated measures ANOVA)

**Highly significant difference between visits ( $p \leq 0.001$, Friedman test or repeated measures ANOVA)

${ }^{a}$ Friedman test or repeated measures ANOVA when parametric test criteria were fulfilled

${ }^{\mathrm{b}}$ Wilcoxon signed-rank or $t$-tests when parametric test criteria were fulfilled

resulted in no significant correlations between LEDD (total and dopamine agonists) and PDSS items).

\section{Discussion}

In this prospective, observational, international, multicenter study including 73 patients with PD, we observed significant beneficial effects of bilateral STN-DBS on QoL, sleep and motor symptoms at 5 months and 24 months follow-up. 
Table 2 Relative changes and effect sizes at 5 months and 24 months follow-up

\begin{tabular}{|c|c|c|c|c|c|c|}
\hline & \multicolumn{2}{|c|}{$\begin{array}{l}\text { Baseline to } \\
5 \text { months } \\
\text { follow-up }\end{array}$} & \multicolumn{2}{|c|}{$\begin{array}{l}\text { Baseline to } \\
24 \text { months } \\
\text { follow-up }\end{array}$} & \multicolumn{2}{|c|}{$\begin{array}{l}5 \text { to } 24 \text { month } \\
\text { follow-up }\end{array}$} \\
\hline & $\mathrm{RC}[\%]$ & $\mathrm{ES}^{\mathrm{a}}$ & $\mathrm{RC}[\%]$ & $\mathrm{ES}^{\mathrm{a}}$ & $\mathrm{RC}[\%]$ & $\mathrm{ES}^{\mathrm{a}}$ \\
\hline PDSS total score* & 23.4 & 0.83 & 9.9 & 0.35 & -11.0 & 0.53 \\
\hline PDSS item 1: 'overall sleep quality’* & 54.8 & 0.74 & 35.7 & 0.48 & -12.3 & 0.31 \\
\hline PDSS item 2: 'sleep onset insomnia' & 23.8 & 0.42 & 11.1 & 0.19 & -10.3 & 0.29 \\
\hline PDSS item 3: 'sleep maintenance insomnia'** & 50.0 & 0.65 & 39.6 & 0.51 & -6.9 & 0.16 \\
\hline PDSS item 4: 'nocturnal restlessness in legs or arms' & 38.0 & 0.50 & 8.0 & 0.11 & -21.7 & 0.44 \\
\hline PDSS item 5: 'fidgeting in bed' & 30.8 & 0.42 & 11.5 & 0.16 & -14.7 & 0.29 \\
\hline PDSS item 6: 'distressing dreams at night'* & 3.8 & 0.11 & -7.6 & 0.21 & -11.0 & 0.33 \\
\hline PDSS item 7: 'distressing hallucinations at night'* & 5.7 & 0.25 & 5.7 & 0.25 & 0.0 & 0.00 \\
\hline PDSS item 8: 'nocturia' & 2.9 & 0.03 & 0.0 & 0.00 & -2.9 & 0.03 \\
\hline PDSS item 9: 'urinary incontinence during motor OFF' & 11.5 & 0.27 & -1.3 & 0.03 & -11.5 & 0.42 \\
\hline PDSS item 10: 'wakefulness due to numbness/tingling'* & 14.5 & 0.29 & 11.6 & 0.24 & -2.5 & 0.07 \\
\hline PDSS item 11: 'wakefulness due to painful muscle cramps' & 18.5 & 0.36 & 9.2 & 0.18 & -7.8 & 0.21 \\
\hline PDSS item 12: 'early waking due to painful posturing'* & 22.2 & 0.38 & 15.9 & 0.27 & -5.2 & 0.13 \\
\hline PDSS item 13: 'tremor on wake up’** & 25.8 & 0.42 & 33.9 & 0.55 & 6.4 & 0.16 \\
\hline PDSS item 14: 'sleep refreshment' & 17.2 & 0.29 & 6.9 & 0.11 & -8.8 & 0.19 \\
\hline PDSS item 15: 'unexpectedly falling asleep at daytime'* & 32.2 & 0.51 & 23.7 & 0.38 & -6.4 & 0.17 \\
\hline PDQ-8 SI & -31.4 & 0.61 & -9.1 & 0.18 & 32.6 & 0.52 \\
\hline HADS-A & -22.7 & 0.36 & -8.6 & 0.14 & 18.3 & 0.26 \\
\hline HADS-D & -20.4 & 0.34 & 6.9 & 0.11 & 35.4 & 0.47 \\
\hline SCOPA-A** & -31.7 & 0.67 & -27.8 & 0.58 & 5.8 & 0.10 \\
\hline SCOPA-B & -27.3 & 0.58 & -13.0 & 0.28 & 19.6 & 0.39 \\
\hline SCOPA-C** & -47.2 & 0.81 & -45.3 & 0.77 & 3.6 & 0.04 \\
\hline LEDD total $(\mathrm{mg})^{* * *}$ & -41.9 & 0.92 & -36.4 & 0.80 & 9.5 & 0.17 \\
\hline LEDD dopamine agonists (mg)** & -47.5 & 0.57 & -54.5 & 0.65 & -13.3 & 0.15 \\
\hline
\end{tabular}

$E S$ effect size, $H A D S$ - $A$ and $-D$ Hospital Anxiety and Depression Scale -anxiety and -depression subscales, $L E D D$ levodopa equivalent daily dose, PDSS Parkinson's Disease Sleep Scale, PDQ-8 SI 8-item Parkinson's Disease Questionnaire Summary Index, $R C$ relative change, $S C O P A-A,-B-C$ Scales for outcomes in Parkinson's disease-motor examination, -activities of daily living, -motor complications

*'small' effect size from baseline to 24 months follow-up

** 'moderate' effect size from baseline to 24 months follow-up

**** 'large' effect size from baseline to 24 months follow-up

aEffect sizes: 'small' (0.20-0.49), 'moderate' (0.50-0.79) and 'large' $(\geq 0.80)$

\section{Effects of STN-DBS on specific aspects of sleep}

The following specific aspects of sleep in PD significantly changed in the longitudinal follow-up of the study:

- Sleep onset and maintenance insomnia (items 2 and 3): in line with previous studies, we observed an improvement of both types of insomnia at short-term follow-up [25]. Studies using polysomnography support these findings with evidence of improvements of sleep continuity and depth [3], total sleep time and efficiency [1], and wakefulness after sleep onset which correlated with an improvement of the PDSS total score [37].
- Nocturnal restlessness (items 4 and 5): in line with previous studies, we observed an improvement of nocturnal restlessness at short term-follow-up [3, 4, 25].

- Nocturnal psychosis (items 6 and 7): previous studies have reported conflicting results for nocturnal psychosis. A study by Peppe et al. including five patients with PD reported a significant improvement of 'distressing dreams at night' at short-term follow-up in pedunculopontine DBS [39]. In contrast, a study by Hjort et al. including ten patients with PD undergoing STN-DBS found no evidence for an improvement of this aspect [25] which was confirmed by the results in our cohort. As neither study reported an improvement of 'distressing hallucinations at night', the present study is the first one to report a beneficial effect of STN-DBS on this aspect at 
Table 3 Spearman correlations between outcomes at 24 months follow-up

\begin{tabular}{|c|c|c|c|c|c|c|c|c|}
\hline & & PDSS & $\begin{array}{l}\text { PDQ-8 } \\
\text { Summary } \\
\text { Index }\end{array}$ & HADS-A & HADS-D & SCOPA-A & SCOPA-B & SCOPA-C \\
\hline \multirow[t]{3}{*}{ PDQ-8 SI } & rho & $-0.322 * *$ & & & & & & \\
\hline & $p$ & 0.007 & & & & & & \\
\hline & $n$ & 70 & & & & & & \\
\hline \multirow[t]{3}{*}{ HADS-A } & rho & -0.161 & $0.444 * *$ & & & & & \\
\hline & $p$ & 0.191 & $<0.001$ & & & & & \\
\hline & $n$ & 68 & 71 & & & & & \\
\hline \multirow[t]{3}{*}{ HADS-D } & rho & -0.100 & $0.318 * *$ & $0.561 * *$ & & & & \\
\hline & $p$ & 0.418 & 0.007 & $<0.001$ & & & & \\
\hline & $n$ & 68 & 71 & 71 & & & & \\
\hline \multirow[t]{3}{*}{ SCOPA-A } & rho & -0.042 & $.239 *$ & 0.071 & 0.086 & & & \\
\hline & $p$ & 0.741 & 0.050 & 0.571 & 0.491 & & & \\
\hline & $n$ & 65 & 68 & 67 & 67 & & & \\
\hline \multirow[t]{3}{*}{ SCOPA-B } & rho & -0.140 & $0.311 * *$ & 0.144 & $0.295^{*}$ & $0.570 * *$ & & \\
\hline & $p$ & 0.251 & 0.008 & 0.234 & 0.013 & $<0.001$ & & \\
\hline & $n$ & 69 & 72 & 70 & 70 & 68 & & \\
\hline \multirow[t]{3}{*}{ SCOPA-C } & rho & $-.341 * *$ & $0.298^{*}$ & $0.266^{*}$ & 0.089 & -0.008 & 0.195 & \\
\hline & $p$ & 0.004 & 0.011 & 0.026 & 0.462 & 0.951 & 0.101 & \\
\hline & $n$ & 69 & 72 & 70 & 70 & 68 & 72 & \\
\hline \multirow{3}{*}{$\begin{array}{l}\text { LEDD } \\
\text { total }\end{array}$} & rho & -0.006 & -0.092 & -0.116 & 0.036 & -0.145 & -0.191 & $-0.270^{*}$ \\
\hline & $p$ & 0.963 & 0.446 & 0.342 & 0.767 & 0.247 & 0.113 & 0.024 \\
\hline & $n$ & 68 & 71 & 69 & 69 & 66 & 70 & 70 \\
\hline \multirow{3}{*}{$\begin{array}{l}\text { LEDD } \\
\text { dopamine } \\
\text {-agonists }\end{array}$} & rho & -0.056 & 0.084 & 0.188 & 0.161 & -0.016 & -0.207 & -0.147 \\
\hline & $p$ & 0.644 & 0.478 & 0.117 & 0.179 & 0.894 & 0.081 & 0.219 \\
\hline & $n$ & 68 & 71 & 69 & 69 & 66 & 70 & 70 \\
\hline
\end{tabular}

Bold font highlights significant results

Higher PDSS total scores indicate less sleep-wake disturbances. Higher test PDQ-8 SI, HADS-A and -D, SCOPA-A, -B, and -C indicate more impairment of specific symptoms. Therefore, significant correlations with negative correlation coefficients between PDSS total and PDQ-8 SI and SCOPA-C indicate that an improvement of sleep is associated with improvements of QoL and motor complications

$H A D S-A$ and $-D$ Hospital Anxiety and Depression Scale-anxiety and -depression subscales, LEDD levodopa equivalent daily dose, PDSS Parkinson's Disease Sleep Scale, PDQ-8 SI 8-item Parkinson's Disease Questionnaire Summary Index, rho Spearman's correlation coefficient, SCOPA-A, $-B$ and $-C$ Scales for outcomes in Parkinson's Disease-motor examination, -activities of daily living, and -motor complications

* Significant correlation at the 0.05 level (2-tailed)

** Significant correlation at the 0.01 level (2-tailed) short-term follow-up. A connection to changes in dopaminergic medication seems possible, as the postoperative total LEDD reduction was $>40 \%$ at 5 months and $>35 \%$ at 24 months follow-up. However, correlation analyses provide no evidence for a linear relationship between improvements of total or dopamine agonists LEDD reduction and an improvement of specific PDSS items, such as nocturnal psychosis. Further studies are needed to investigate this issue.

- Nocturnal urinary symptoms (items 8 and 9): confirming negative results from previous studies [4, 6, 25], we found no effects of STN-DBS on 'Nocturia'. However, to our knowledge, the present study is the first one to report an improvement of 'urinary incontinence during motor OFF' at 5 months follow-up. This observation could be explained by an improvement of nocturnal motor symptoms.

- Nocturnal sensorimotor symptoms (PDSS items 10-13): In line with previous studies, we found beneficial effects of bilateral STN-DBS on all PDSS items for nocturnal sensorimotor symptoms [25] at short-term 5 months follow-up.

- Sleep refreshment (item 14): confirming previous studies we found a significant improvement of sleep refreshment at short-term follow-up [4]. Contrary to the results pub- 
lished by Choi et al., we observed a significant beneficial effect on sleep refreshment at 24 months follow-up.

- Daytime sleepiness (item 15): previous studies have reported negative results for this aspect of sleep-wake disturbances at short-term [25] and long-term [6, 30] follow-up after STN-DBS. To our knowledge, the present study is the first one to report significant beneficial effects of STN-DBS on daytime sleepiness at long-term follow-up. Although a link between dopaminergic medication, in particular dopamine agonists, and daytime sleepiness or sleep attacks is well known [26], we found no evidence for a linear relationship between a total or dopamine agonists LEDD reduction and an improvement of this PDSS item. Further studies are needed to investigate possible higher-order relationships which might result from patient-specific adverse events thresholds.

- Overall sleep quality (item 1 ): in line with previous studies, the overall quality of sleep significantly improved at short-term $[4,25]$ and 24 months long-term followup [6]. This may be a result of the above mentioned improvements of specific PDSS domains.

\section{Mechanisms of effects of STN-DBS on sleep}

Sleep-wake disturbances are a collection of different symptoms and result from multi-neuropeptide dysfunction including the central dopaminergic, hypocretinergic, noradrenergic, and serotonergic systems [21]. As the pathomechanisms of sleep-wake disturbances are diverse, various mechanisms of action may influence the effects of STN-DBS [10]:

- A direct modulation of the basal ganglia-thalamo-cortico loops may influence neural activity, e.g., in the motor circuitry which in turn could improve motor symptomsrelated sleep disorder [29]. Furthermore, a modulation of the medial thalamus could, e.g., improve restlessness in legs or arms [19]. Future studies are required to assess the role of directional DBS towards subregions of the STN and the adjacent target region [16, 17, 40]. Another possible explanation could be mediated through projections from the STN to the globus pallidus externus as electrophysiological animal studies have shown that during STN-DBS the activity in the globus pallidus externus is increased which may result in an improvement of sleep [22, 24, 27, 34, 41].

- A spread of current to nuclei in proximity of the STN, such as the pedunculopontine nucleus, which has previously been associated with an improvement of nighttime sleep and daytime sleepiness $[39,43]$. While the exact borders of the pedunculopontine nucleus are difficult to define [23], a location approximately $5 \mathrm{~mm}$ ventral of the STN with even closer projections has been discussed [36].
- The reduction of dopaminergic medication requirements below patient-specific thresholds may at least in part influence sleep-wake disturbances, such as daytime sleepiness [26] or hallucinations [48]. Further studies are needed to distinguish between stimulation and medication effects on these NMS.

\section{Relationship of sleep and other outcome parameters}

The significant correlation between improvements of PDSS total score and PDQ-8 SI indicates the close connection between sleep and QoL outcomes. The fact that Spearman correlations showed a significant relationship between improvements of motor complications and sleep symptoms is consistent with the observation that nocturnal motor symptoms, such as painful dystonic posturing, were improved at 24 months-follow-up and indicate the relative importance of nocturnal motor symptoms for subjective sleep outcomes. The observation that improvements of PDSS total score and HADS-A and -D were not significantly correlated indicates that sleep and mood disorders are separately influenced by STN-DBS. Psychotropic medication was started or switched only in 2 out of 73 patients of our cohort during the course of this study. Therefore, it seems unlikely that observed beneficial effects of STN-DBS on sleep symptoms were based on these drugs. Additionally, as discussed above no relationship was found between changes of sleep symptoms and changes of dopaminergic and specifically dopamine agonist medication. As also the medication changes from 5 to 24 months follow-up were not correlated with PDSS changes, one might argue that medication side effects are unlikely causes for the observed changes of sleep symptoms between follow-up visits and therefore factors like disease progression or chronic DBS treatment itself might also contribute to the observed changes. Further studies are needed to investigate this issue.

\section{Limitations}

A number of limitations should be considered in this study. Although the cohort size in our study $(n=73)$ is one of the biggest in studies of its kind, the study cohort is relatively small and further prospective studies are required to confirm these findings. The multicenter design of our study is likely to reduce systematic bias caused by single center studies. We did not include laboratory-assisted assessments of sleep, such as multiple sleep latency test or polysomnography for sleep architecture as these measures require additional equipment and are rather costly. However, we were interested in a pragmatic assessment of a wide range of sleep-wake disturbances including complex symptoms, such as nocturia, nocturnal psychosis, motor state-related sleep 
symptoms, and sleep refreshment, which cannot be captured by polysomnography. Due to the design of our database as a prospective, observational study, motor assessments were recorded in ON states (MedON/StimON) [15]. Although the current study did not find a relationship/correlation between change in motor exam and change in sleep, this is still an important potential contributor to the improvement in sleep and the relationship may have been masked because participants were only evaluated in ON states. Many of the studies that did find a relationship between motor and sleep outcomes used polysomnography. Furthermore, systematic follow-up examinations of motor states with and without medication and DBS could also provide useful information on patients' non-dopaminergic, non-motor characteristics which may contribute to their sleep-wake disturbances [21]. Furthermore, this study did not assess apathy in detail and analyze the interplay between apathy and sleep/fatigue observed in previous studies by Eugster et al. and Bargiotas et al. $[2,20]$.

\section{Conclusion}

We observed significant long-term beneficial effects of STNDBS on overall quality of sleep and a wide range of specific sleep symptoms, such as sleep maintenance insomnia, early waking due to painful posturing, tremor on wake up, and daytime sleepiness. Improvements of sleep symptoms seem to be, at least in part, mediated by nocturnal motor symptoms. A significant correlation between sleep and QoL outcomes at 24 months follow-up epitomizes the relative importance of sleep symptoms for the holistic assessment of DBS outcomes.

Acknowledgements Open Access funding provided by Projekt DEAL. Members of the Non-motor Parkinson's Disease Study Group (NM-PDSG) of the International Parkinson's Disease and Movement Disorders Society (IPMDS): Steering Committee: Kallol Ray-Chaudhuri; Professor, FRCP (Edin) FRCP (Lond) DSc, MD (King's College London, London, United Kingdom; Chair); Angelo Antonini; Professor, MD/ $\mathrm{PhD}$ (IRCCS Hospital San Camillo, Venice, Italy); Pablo MartinezMartin; Professor, MD/PhD (Carlos III Institute of Health, Madrid, Spain); Per Odin; Professor, MD/PhD (Klinikum-Bremerhaven, Germany, and Skane University Hospital, Lund, Sweden); Anette Schrag; $\mathrm{MD} / \mathrm{PhD}$ (University College London, London, United Kingdom); Daniel Weintraub; Professor (Associate), MD/PhD (University of Pennsylvania, Philadelphia, PA, USA). Standing Members: Paolo Barone;

Professor, MD/PhD (University of Naples, Italy); David J Brooks; Professor, MD/PhD, D.Sc., F.R.C.P., F.Med.Sci. (University College London, London, United Kingdom); Richard G. Brown; Professor, $\mathrm{MD} / \mathrm{PhD}$, MPhil (King's College London, London, United Kingdom); Peter Jenner; Professor, MD/PhD, D.Sc. (King's College London, London, United Kingdom); B Jeon; Professor, MD/PhD (Seoul National University Hospital, Seoul, Korea); Kelly Lyons; Professor, MD/PhD (University of Kansas Medical Center, Kansas City, KS, USA); Nicola Pavese; Professor (Associate), MD/PhD (Aarhus University Hospital,
Århus, Denmark, and Imperial College London, London, United Kingdom); Marios Politis; MD/PhD, MSc, DIC (King's College London, London, United Kingdom; Ronald B. Postuma; Professor (Associate), MD, MSc (McGill University, Montreal, Canada); Anthony Schapira; Professor, MD/PhD, DSc, FRCP, FMedSc (University College London, London, United Kingdom); Fabrizio Stocchi; Professor, $\mathrm{MD} / \mathrm{PhD}$ (IRCCS, San Raffaele Rome, Rome Italy); Lars Timmermann; Professor, MD/PhD (University Hospital Cologne, Cologne, Germany); Yoshio Tsuboi; Professor, MD/PhD (Fukuoka University, Fukuoka, Japan). Managerial and Coordination: Alexandra Rizos; MSc (King's College Hospital, London, United Kingdom); Anna Sauerbier; MD (King's College Hospital, London, United Kingdom).

Author contributions HSD: study concept and design, data acquisition, data analysis, drafting of the manuscript. KR-C: study concept and design, critical revision of the manuscript. KA: surgical intervention, critical revision of the manuscript. LS: data acquisition, critical revision of the manuscript. PM: data acquisition, critical revision of the manuscript. MS: data acquisition, critical revision of the manuscript. AR: data acquisition, critical revision of the manuscript. MS: data acquisition, critical revision of the manuscript. STJ: critical revision of the manuscript. PR: data acquisition, critical revision of the manuscript. MS: data acquisition, critical revision of the manuscript. VV-V: surgical intervention, critical revision of the manuscript. JE: surgical intervention, critical revision of the manuscript. AA: critical revision of the manuscript. PM-M: critical revision of the manuscript. LT: study concept and design, critical revision of the manuscript.

Funding This paper is independent research funded by the German Research Foundation (Grant KFO 219), the National Institute of Health Research (NIHR) Mental Health Biomedical Research Centre and Dementia Unit at South London and Maudsley NHS Foundation Trust and King's College London. Additionally an unrestricted peer reviewed educational grant was provided to support coordination of the UK dataset from Medtronic.

Data availability The data included in this study is available on request to the corresponding author. The data are not publicly available due to their containing information that could compromise the privacy of the participants.

\section{Compliance with ethical standards}

Conflicts of interest Haidar S. Dafsari has received grants by the Prof. Dr. Klaus Thiemann Foundation, the Koeln Fortune Program, and the Felgenhauer Foundation and honoraria by Boston Scientific and Medtronic. K. Ray Chaudhuri has received funding from Parkinson's UK, NIHR, UCB, and the European Union; he received honoraria from UCB, Abbott, Britannia, US Worldmeds, and Otsuka Pharmaceuticals; and acted as a consultant for AbbVie, UCB, and Britannia. Keyoumars Ashkan has received honoraria for educational meetings, travel and consultancy from Medtronic, Abbott Laboratories and Boston Scientific. Lena Sachse reports no disclosures. Picabo Mahlstedt reports no disclosures. Monty Silverdale has received honoraria for educational meetings/travel/accommodation from Medtronic and grants from Parkinson's UK, NIHR and MJFF. Alexandra Rizos was supported by a grant from PDNMG and the NIHR Comprehensive Research Network South London. Marian Strack has received grants from the Koeln Fortune Program. Stefanie T. Jost reports no disclosures. Paul Reker has received honoraria from AbbVie. Michael Samuel has received honoraria for educational meetings/travel/accommodation from Medtronic, St. Jude Medical, and UCB, grants from Parkinson's UK and Ipsen, and has acted as a consultant for Medtronic and St. Jude Medical. Veerle Visser-Vandewalle is a member of the advisory 
boards and reports consultancies for Medtronic, Boston Scientific and Abbott Laboratories. She received a grant from SAPIENS Steering Brain Stimulation (now Medtronic Eindhoven design center). Julian Evans reports no financial disclosures. Angelo Antonini reports personal consultancy fees from Sunovion, Zambon, AbbVie, Angelini, UCB, Boehringer Ingelheim, Cynapsus Therapeutics, GE, Medtronic, Boston Scientific, Mundipharma, Ever Neuro Pharma, grants from Horizon2020 Project No 643706, owns Patent WO2015110261-A1, owns shares from PD Neurotechnology Limited. Pablo Martinez-Martin has received grants from Parkinson's UK, Carlos III Institute of Health (FIS), IMSERSO, the Reina Sofia Foundation, and the Parkinson's Disease Non-Motor Group, and has received honorarium from TEVA, Lundbeck, Italfarmaco, AbbVie, National School of Public Health (ISCIII), Complutense University, and Editorial Viguera. Lars Timmermann reports grants, personal fees and non-financial support from SAPIENS Steering Brain Stimulation, Medtronic, Boston Scientific and Abbott Laboratories and has received payments from Bayer Healthcare, UCB Schwarz Pharma, and Archimedes Pharma and also honoraria as a speaker on symposia sponsored by Teva Pharma, Lundbeck Pharma, Bracco, Gianni PR, Medas Pharma, UCB Schwarz Pharma, Desitin Pharma, Boehringer Ingelheim, GSK, Eumecom, Orion Pharma, Medtronic, Boston Scientific, Cephalon, Abbott, GE Medical, Archimedes, and Bayer.

Open Access This article is licensed under a Creative Commons Attribution 4.0 International License, which permits use, sharing, adaptation, distribution and reproduction in any medium or format, as long as you give appropriate credit to the original author(s) and the source, provide a link to the Creative Commons licence, and indicate if changes were made. The images or other third party material in this article are included in the article's Creative Commons licence, unless indicated otherwise in a credit line to the material. If material is not included in the article's Creative Commons licence and your intended use is not permitted by statutory regulation or exceeds the permitted use, you will need to obtain permission directly from the copyright holder. To view a copy of this licence, visit http://creativecommons.org/licenses/by/4.0/.

\section{References}

1. Arnulf I, Bejjani BP, Garma L, Bonnet AM, Houeto JL, Damier P, Derenne JP, Agid Y (2000) Improvement of sleep architecture in PD with subthalamic nucleus stimulation. Neurology 55:1732-1734

2. Bargiotas P, Eugster L, Oberholzer M, Debove I, Lachenmayer ML, Mathis J, Pollo C, Schupbach WMM, Bassetti CL (2017) Sleep-wake functions and quality of life in patients with subthalamic deep brain stimulation for Parkinson's disease. PLoS One 12:e0190027

3. Baumann-Vogel H, Imbach LL, Surucu O, Stieglitz L, Waldvogel D, Baumann CR, Werth E (2017) The impact of subthalamic deep brain stimulation on sleep-wake behavior: a prospective electrophysiological study in 50 Parkinson patients. Sleep. https://doi. org/10.1093/sleep/zsx033

4. Chahine LM, Ahmed A, Sun Z (2011) Effects of STN DBS for Parkinson's disease on restless legs syndrome and other sleeprelated measures. Parkinsonism Relat Disord 17:208-211

5. Chaudhuri KR, Pal S, DiMarco A, Whately-Smith C, Bridgman K, Mathew R, Pezzela FR, Forbes A, Hogl B, Trenkwalder C (2002) The Parkinson's disease sleep scale: a new instrument for assessing sleep and nocturnal disability in Parkinson's disease. J Neurol Neurosurg Psychiatry 73:629-635
6. Choi JH, Kim HJ, Lee JY, Yoo D, Im JH, Paek SH, Jeon B (2019) Long-term effects of bilateral subthalamic nucleus stimulation on sleep in patients with Parkinson's disease. PLoS One 14:e0221219

7. Cicolin A, Lopiano L, Zibetti M, Torre E, Tavella A, Guastamacchia G, Terreni A, Makrydakis G, Fattori E, Lanotte MM, Bergamasco B, Mutani R (2004) Effects of deep brain stimulation of the subthalamic nucleus on sleep architecture in parkinsonian patients. Sleep Med 5:207-210

8. Cohen J (1977) Statistical power analysis for the behavioral sciences. Academic Press, New York

9. Dafsari HS, Martinez-Martin P, Rizos A, Trost M, Dos Santos Ghilardi MG, Reddy P, Sauerbier A, Petry-Schmelzer JN, Kramberger M, Borgemeester RWK, Barbe MT, Ashkan K, Silverdale M, Evans J, Odin P, Fonoff ET, Fink GR, Henriksen T, Ebersbach G, Pirtosek Z, Visser-Vandewalle V, Antonini A, Timmermann L, Ray Chaudhuri K;, EUROPAR and the IPMDS Non-Motor PD Study Group (2019) EuroInf 2: subthalamic stimulation, apomorphine, and levodopa infusion in Parkinson's disease. Mov Disord 34(353):365

10. Dafsari HS, Petry-Schmelzer JN, Ray-Chaudhuri K, Ashkan K, Weis L, Dembek TA, Samuel M, Rizos A, Silverdale M, Barbe MT, Fink GR, Evans J, Martinez-Martin P, Antonini A, VisserVandewalle V, Timmermann L, EUROPAR, IPMDS Non Motor PD Study Group (2018) Non-motor outcomes of subthalamic stimulation in Parkinson's disease depend on location of active contacts. Brain Stimul 11(904):912

11. Dafsari HS, Ray-Chaudhuri K, Mahlstedt P, Sachse L, Steffen JK, Petry-Schmelzer JN, Dembek TA, Reker P, Barbe MT, VisserVandewalle V, Fink GR, Timmermann L (2019) Beneficial effects of bilateral subthalamic stimulation on alexithymia in Parkinson's disease. Eur J Neurol 26:222-e217

12. Dafsari HS, Reker P, Silverdale M, Reddy P, Pilleri M, MartinezMartin P, Rizos A, Perrier E, Weiss L, Ashkan K, Samuel M, Evans J, Visser-Vandewalle V, Antonini A, Ray-Chaudhuri K, Timmermann L, EUROPAR and the IPMDS Non-Motor PD Study Group (2018) Subthalamic stimulation improves quality of life of patients aged 61 years or older with short duration of Parkinson's disease. Neuromodul J Int Neuromodul Soc 21:532-540

13. Dafsari HS, Reker P, Stalinski L, Silverdale M, Rizos A, Ashkan K, Barbe MT, Fink GR, Evans J, Steffen J, Samuel M, Dembek TA, Visser-Vandewalle V, Antonini A, Ray-Chaudhuri K, Martinez-Martin P, Timmermann L, EUROPAR and the IPMDS (International Parkinson's and Movement Disorders Society) Non-Motor Parkinson's Disease Study Group (2018) Quality of life outcome after subthalamic stimulation in Parkinson's disease depends on age. Mov Disord 33:99-107

14. Dafsari HS, Silverdale M, Strack M, Rizos A, Ashkan K, Mahlstedt P, Sachse L, Steffen J, Dembek TA, Visser-Vandewalle V, Evans J, Antonini A, Martinez-Martin P, Ray-Chaudhuri K, Timmermann L, EUROPAR and the IPMDS Non Motor PD Study Group (2018) Nonmotor symptoms evolution during 24 months of bilateral subthalamic stimulation in Parkinson's disease. Mov Disord 33:421-430

15. Dafsari HS, Weiss L, Silverdale M, Rizos A, Reddy P, Ashkan K, Evans J, Reker P, Petry-Schmelzer JN, Samuel M, Visser-Vandewalle V, Antonini A, Martinez-Martin P, Ray-Chaudhuri K, Timmermann L, EUROPAR and the IPMDS Non Motor PD Study (2018) Short-term quality of life after subthalamic stimulation depends on non-motor symptoms in Parkinson's disease. Brain Stimul 11:867-874

16. Dembek TA, Reker P, Visser-Vandewalle V, Wirths J, Treuer H, Klehr M, Roediger J, Dafsari HS, Barbe MT, Timmermann L (2017) Directional DBS increases side-effect thresholds-a prospective, double-blind trial. Mov Disord 32:1380-1388 
17. Dembek TA, Roediger J, Horn A, Reker P, Oehrn C, Dafsari HS, Li N, Kuhn AA, Fink GR, Visser-Vandewalle V, Barbe MT, Timmermann L (2019) Probabilistic sweet spots predict motor outcome for deep brain stimulation in Parkinson disease. Ann Neurol 86:527-538

18. Deuschl G, Schade-Brittinger C, Krack P, Volkmann J, Schafer H, Botzel K, Daniels C, Deutschlander A, Dillmann U, Eisner W, Gruber D, Hamel W, Herzog J, Hilker R, Klebe S, Kloss M, Koy J, Krause M, Kupsch A, Lorenz D, Lorenzl S, Mehdorn HM, Moringlane JR, Oertel W, Pinsker MO, Reichmann H, Reuss A, Schneider GH, Schnitzler A, Steude U, Sturm V, Timmermann L, Tronnier V, Trottenberg T, Wojtecki L, Wolf E, Poewe W, Voges J, German Parkinson Study Group, Neurostimulation Section (2006) A randomized trial of deep-brain stimulation for Parkinson's disease. N Engl J Med 355(896):908

19. Driver-Dunckley E, Evidente VGH, Adler CH, Hillman R, Hernandez J, Fletcher G, Lyons MK (2006) Restless legs syndrome in Parkinson's disease patients may improve with subthalamic stimulation. Mov Disord 21:1287-1289

20. Eugster L, Bargiotas P, Bassetti CL, Michael Schuepbach WM (2016) Deep brain stimulation and sleep-wake functions in Parkinson's disease: a systematic review. Parkinsonism Relat Disord 32:12-19

21. Fraigne JJ, Torontali ZA, Snow MB, Peever JH (2015) REM sleep at its core-circuits, neurotransmitters, and pathophysiology. Front Neurol 6:123

22. Hahn PJ, Russo GS, Hashimoto T, Miocinovic S, Xu W, McIntyre CC, Vitek JL (2008) Pallidal burst activity during therapeutic deep brain stimulation. Exp Neurol 211:243-251

23. Hamani C, Aziz T, Bloem BR, Brown P, Chabardes S, Coyne T, Foote K, Garcia-Rill E, Hirsch EC, Lozano AM, Mazzone PAM, Okun MS, Hutchison W, Silburn P, Zrinzo L, Alam M, Goetz L, Pereira E, Rughani A, Thevathasan W, Moro E, Krauss JK (2016) Pedunculopontine nucleus region deep brain stimulation in Parkinson disease: surgical anatomy and terminology. Stereotact Funct Neurosurg 94:298-306

24. Hashimoto T, Elder CM, Okun MS, Patrick SK, Vitek JL (2003) Stimulation of the subthalamic nucleus changes the firing pattern of pallidal neurons. J Neurosci 23:1916-1923

25. Hjort N, Ostergaard K, Dupont E (2004) Improvement of sleep quality in patients with advanced Parkinson's disease treated with deep brain stimulation of the subthalamic nucleus. Mov Disord 19:196-199

26. Homann CN, Wenzel K, Suppan K, Ivanic G, Kriechbaum N, Crevenna $R$, Ott E (2002) Sleep attacks in patients taking dopamine agonists: review. Br Med J 324:1483-1487

27. Kita H, Tachibana Y, Nambu A, Chiken S (2005) Balance of monosynaptic excitatory and disynaptic inhibitory responses of the globus pallidus induced after stimulation of the subthalamic nucleus in the monkey. J Neurosci 25:8611-8619

28. Krack P, Batir A, Van Blercom N, Chabardes S, Fraix V, Ardouin C, Koudsie A, Limousin PD, Benazzouz A, LeBas JF, Benabid AL, Pollak P (2003) Five-year follow-up of bilateral stimulation of the subthalamic nucleus in advanced Parkinson's disease. N Engl J Med 349:1925-1934

29. Krack P, Hariz MI, Baunez C, Guridi J, Obeso JA (2010) Deep brain stimulation: from neurology to psychiatry? Trends Neurosci 33:474-484

30. Lyons KE, Pahwa R (2006) Effects of bilateral subthalamic nucleus stimulation on sleep, daytime sleepiness, and early morning dystonia in patients with Parkinson disease. J Neurosurg 104:502-505

31. Marinus J, Visser M, Stiggelbout AM, Rabey JM, MartinezMartin P, Bonuccelli U, Kraus PH, van Hilten JJ (2004) A short scale for the assessment of motor impairments and disabilities in Parkinson's disease: the SPES/SCOPA. J Neurol Neurosurg Psychiatry 75:388-395

32. Martinez-Martin P, Benito-Leon J, Burguera JA, Castro A, Linazasoro G, Martinez-Castrillo JC, Valldeoriola F, Vazquez A, Vivancos F, del Val J, van Blercom N, Frades B (2005) The SCOPAMotor Scale for assessment of Parkinson's disease is a consistent and valid measure. J Clin Epidemiol 58:674-679

33. Martinez-Martin P, Jeukens-Visser M, Lyons KE, RodriguezBlazquez C, Selai C, Siderowf A, Welsh M, Poewe W, Rascol O, Sampaio C, Stebbins GT, Goetz CG, Schrag A (2011) Healthrelated quality-of-life scales in Parkinson's disease: critique and recommendations. Mov Disord 26:2371-2380

34. Miocinovic S, Parent M, Butson CR, Hahn PJ, Russo GS, Vitek JL, McIntyre CC (2006) Computational analysis of subthalamic nucleus and lenticular fasciculus activation during therapeutic deep brain stimulation. J Neurophysiol 96:1569-1580

35. Monaca C, Ozsancak C, Jacquesson JM, Poirot I, Blond S, Destee A, Guieu JD, Derambure P (2004) Effects of bilateral subthalamic stimulation on sleep in Parkinson's disease. J Neurol 251:214-218

36. Moreau C, Defebvre L, Destee A, Bleuse S, Clement F, Blatt JL, Krystkowiak P, Devos D (2008) STN-DBS frequency effects on freezing of gait in advanced Parkinson disease. Neurology $71: 80-84$

37. Nishida N, Murakami T, Kadoh K, Tohge R, Yamanegi M, Saiki H, Ueda K, Matsumoto S, Ishikawa M, Takahashi JA, Toda H (2011) Subthalamic nucleus deep brain stimulation restores normal rapid eye movement sleep in Parkinson's disease. Mov Disord 26:2418-2422

38. Odekerken VJ, van Laar T, Staal MJ, Mosch A, Hoffmann CF, Nijssen PC, Beute GN, van Vugt JP, Lenders MW, Contarino MF, Mink MS, Bour LJ, van den Munckhof P, Schmand BA, de Haan RJ, Schuurman PR, de Bie RM (2013) Subthalamic nucleus versus globus pallidus bilateral deep brain stimulation for advanced Parkinson's disease (NSTAPS study): a randomised controlled trial. Lancet Neurol 12:37-44

39. Peppe A, Pierantozzi M, Baiamonte V, Moschella V, Caltagirone C, Stanzione P, Stefani A (2012) Deep brain stimulation of pedunculopontine tegmental nucleus: role in sleep modulation in advanced Parkinson disease patients: one-year follow-up. Sleep 35:1637-1642

40. Petry-Schmelzer JN, Krause M, Dembek TA, Horn A, Evans J, Ashkan K, Rizos A, Silverdale M, Schumacher W, Sack C, Loehrer PA, Fink GR, Fonoff ET, Martinez-Martin P, Antonini A, Barbe MT, Visser-Vandewalle V, Ray-Chaudhuri K, Timmermann L, Dafsari HS, EUROPAR and the IPMDS Non-Motor PD Study Group (2019) Non-motor outcomes depend on location of neurostimulation in Parkinson's disease. Brain 142:3592-3604

41. Qiu MH, Chen MC, Wu J, Nelson D, Lu J (2016) Deep brain stimulation in the globus pallidus externa promotes sleep. Neuroscience 322:115-120

42. Rodriguez-Blazquez C, Frades-Payo B, Forjaz MJ, de PedroCuesta J, Martinez-Martin P, Longitudinal Parkinson's Disease Patient Study Group (2009) Psychometric attributes of the Hospital Anxiety and Depression Scale in Parkinson's disease. Mov Disord 24:519-525

43. Romigi A, Placidi F, Peppe A, Pierantozzi M, Izzi F, Brusa L, Galati S, Moschella V, Marciani MG, Mazzone P, Stanzione P, Stefani A (2008) Pedunculopontine nucleus stimulation influences REM sleep in Parkinson's disease. Eur J Neurol 15:e64-65

44. Scaravilli T, Gasparoli E, Rinaldi F, Polesello G, Bracco F (2003) Health-related quality of life and sleep disorders in Parkinson's disease. Neurol Sci 24:209-210

45. Schuepbach WMM, Tonder L, Schnitzler A, Krack P, Rau J, Hartmann A, Halbig TD, Pineau F, Falk A, Paschen L, Paschen S, Volkmann J, Dafsari HS, Barbe MT, Fink GR, Kuhn A, Kupsch A, Schneider GH, Seigneuret E, Fraix V, Kistner A, Chaynes PP, 
Ory-Magne F, Brefel-Courbon C, Vesper J, Wojtecki L, Derrey S, Maltete D, Damier P, Derkinderen P, Sixel-Doring F, Trenkwalder C, Gharabaghi A, Wachter T, Weiss D, Pinsker MO, Regis JM, Witjas T, Thobois S, Mertens P, Knudsen K, Schade-Brittinger C, Houeto JL, Agid Y, Vidailhet M, Timmermann L, Deuschl G, EARLYSTIM Study Group (2019) Quality of life predicts outcome of deep brain stimulation in early Parkinson disease. Neurology 92:e1109-e1120

46. Steffen JK, Reker P, Mennicken FK, Dembek TA, Dafsari HS, Fink GR, Visser-Vandewalle V, Barbe MT (2020) Bipolar directional deep brain stimulation in essential and parkinsonian tremor. Neuromodul Technol Neural Interface. https://doi.org/10.1111/ ner. 13109

47. Storch A, Schneider CB, Wolz M, Sturwald Y, Nebe A, Odin P, Mahler A, Fuchs G, Jost WH, Chaudhuri KR, Koch R, Reichmann H, Ebersbach G (2013) Nonmotor fluctuations in Parkinson disease: severity and correlation with motor complications. Neurology 80:800-809
48. Stowe R, Ives N, Clarke CE, Handley K, Furmston A, Deane K, van Hilten JJ, Wheatley K, Gray R (2011) Meta-analysis of the comparative efficacy and safety of adjuvant treatment to levodopa in later Parkinson's disease. Mov Disord 26:587-598

49. Tomlinson CL, Stowe R, Patel S, Rick C, Gray R, Clarke CE (2010) Systematic review of levodopa dose equivalency reporting in Parkinson's disease. Mov Disord 25:2649-2653

50. Tse W, Liu Y, Barthlen GM, Hälbig TD, Tolgyesi SV, Gracies J-M, Olanow CW, Koller WC (2005) Clinical usefulness of the Parkinson's disease sleep scale. Parkinsonism Relat Disord 11:317-321

51. Williams A, Gill S, Varma T, Jenkinson C, Quinn N, Mitchell R, Scott R, Ives N, Rick C, Daniels J, Patel S, Wheatley K (2010) Deep brain stimulation plus best medical therapy versus best medical therapy alone for advanced Parkinson's disease (PD SURG trial): a randomised, open-label trial. Lancet Neurol 9:581-591

\section{Affiliations}

\section{Haidar S. Dafsari ${ }^{1,2}$ (1) K. Ray-Chaudhuri ${ }^{2,3} \cdot$ Keyoumars Ashkan $^{2} \cdot$ Lena Sachse $^{1} \cdot$ Picabo Mahlstedt $^{1}$. Monty Silverdale ${ }^{4}$ - Alexandra Rizos ${ }^{2} \cdot$ Marian Strack $^{1}$. Stefanie T. Jost ${ }^{1} \cdot$ Paul Reker $^{1} \cdot$ Michael Samuel $^{2}$. Veerle Visser-Vandewalle ${ }^{5}$. Julian Evans ${ }^{4} \cdot$ Angelo Antonini $^{6,7} \cdot$ Pablo Martinez-Martin $^{8} \cdot$ Lars Timmermann $^{1,9}$. EUROPAR, the IPMDS Non Motor P.D. Study Group}

1 Department of Neurology, University Hospital Cologne, Kerpenerstr. 62, 50937 Cologne, Germany

2 National Parkinson Foundation International Centre of Excellence, King's College Hospital, London, UK

3 Institute of Psychiatry, Psychology and Neuroscience, King's College London, London, UK

4 Department of Neurology and Neurosurgery, Salford Royal NHS Foundation Trust, Manchester Academic Health Science Centre, University of Manchester, Greater Manchester, UK

5 Department of Stereotaxy and Functional Neurosurgery, University Hospital Cologne, Cologne, Germany
6 Parkinson and Movement Disorders Unit, IRCCS Hospital San Camillo, Venice, Italy

7 Department of Neurosciences (DNS), Padova University, Padova, Italy

8 National Center of Epidemiology and CIBERNED, Carlos III Institute of Health, Madrid, Spain

9 Department of Neurology, University Hospital Giessen and Marburg, Campus Marburg, Marburg, Germany 